\title{
Increasing evidence of the role of Helicobacter pylori SabA in the pathogenesis of gastroduodenal disease
}

\author{
Yoshio Yamaoka \\ Department of Medicine-Gastroenterology, Michael E. DeBakey Veterans Affairs Medical Center and Baylor College of \\ Medicine, Houston, Texas, United States of America.
}

\begin{abstract}
Although infection with Helicobacter pylori always results in chronic active gastritis, only a fraction of those infected develop severe clinical disease. In addition, certain populations with high incidences of $H$. pylori infection, such as those in East Asian countries, have high incidences of gastric cancer, while other highly infected populations, such as those in Africa and South Asia, do not. This phenomenon might be partially explained by differences in the genotypes of $H$. pylori; however, currently no definite $H$. pylori factors can clearly explain it. Recently, the importance of sialic acid binding adhesin (SabA), a novel outer membrane protein in gastroduodenal pathogenesis, has become increasingly apparent. Binding of blood group antigen binding adhesin (BabA) to Lewis $b$ antigen and related fucosylated $A B O$ blood group antigens is probably important in the initial stage of infection. However, when host inflammation increases, expression of sialyl-Lewis $\mathrm{x}$ increases, and $H$. pylori is likely to adhere to the gastric mucosa with SabA. Many of the genes encoding outer membrane proteins undergo phase variation such that not all strains will produce functional proteins, and SabA expression is frequently switched "on" or "off", suggesting that SabA expression can rapidly respond to changing conditions in the stomach or in different regions of the stomach. SabA production is indeed reported to be associated with severe intestinal metaplasia, gastric atrophy, and the development of gastric cancer in both developed and developing countries, confirming the importance of investigating SabA in developing countries.

Key Words: Helicobacter pylori; SabA, gastroduodenal diseases, sialyl-Lewis x/a antigens.
\end{abstract}

J Infect Developing Countries 2008; 2(3):174-181.

Received 6 March 2008 - Accepted 25 April 2008

Copyright (c) 2008 Yamaoka. This is an open access article distributed under the Creative Commons Attribution License, which permits unrestricted use, distribution, and reproduction in any medium, provided the original work is properly cited.

\section{Introduction}

Helicobacter pylori is a gram negative bacterium that colonises the gastric mucosa and causes gastritis, peptic ulcers and gastric malignancy. Although infection with $H$. pylori always results in chronic active gastritis, only a fraction of those infected develop severe clinical disease [1]. In addition, some populations with high incidences of $H$. pylori infection, such as those in East Asian countries, have high incidences of gastric cancer, while other highly infected populations, such as populations in Africa (African enigma) and South Asia (Asian enigma), do not. While these phenomena remain unexplained, host genetics, host immune response, and the relationship of the host response to bacterial virulence factors appear to play critical roles. A number of studies are investigating the roles of putative virulence factors of $H$. pylori, in particular CagA and VacA. CagA and/or VacA producing strains are reported to be related to severe clinical outcomes, especially in Western countries [2-7]. However, the importance of CagA and VacA has not been observed in East Asian countries, where most strains produce CagA and VacA irrespective of the disease $[8,9]$, or in many developing countries, including Colombia [9], Thailand [10] and India [11].

It has been proposed that any $H$. pylori virulence factor should 1) have a disease or other in vivo correlation; 2) be epidemiologically consistent across populations and regions; and 3) be biologically plausible, with an effect that is reduced or eliminated by gene deletion [12]. Based on the second criterion, CagA and VacA might not be the true virulence factors, and therefore, recent searches for other putative virulence factors of $H$. pylori are of great interest.

Epithelial adherence may benefit $H$. pylori by providing better access to epithelial surfaces and may contribute to delivery of bacterial toxins and various effector molecules through the type IV 
secretion mechanisms. Many $H$. pylori strains express adhesin proteins that bind to specific hostcell macromolecule receptors, most of which are members of the outer membrane protein (OMP) family and include the blood group antigen binding adhesin (BabA), outer membrane inflammatory protein (OipA) and sialic acid binding adhesin (SabA). Both BabA and OipA conform to the first and third virulence factors described above and BabA and/or OipA producing strains are also reported to be related to severe clinical outcomes, especially in Western countries [13,14]. However they are again independent of clinical outcomes in several geographic regions including East Asia $[13,15]$.

The sialyl-Lewis $x / a$ antigens $\left(s L e^{x}\right.$ and $\left.s L e^{a}\right)$ serve as the functional receptors for $H$. pylori adherence, and $s L e^{\mathrm{x}}$ and $s L \mathrm{e}^{\mathrm{a}}$ are recognized by SabA [16]. Sialylated glycoconjugates are scant in healthy gastric mucosa; however, the persistent colonization of the human stomach with $H$. pylori leads to dramatic gastric mucosal inflammation, accompanied by the replacement of naturally produced Lewis antigens by sialylated glycans $\left(s L e^{x}\right.$ and $\left.s L e^{a}\right)[16,17]$. The expression of sialylated antigens, in particular $s L e^{a}$, has been reported to be elevated in gastric carcinoma [18]. These data suggest that SabA could play important roles in gastroduodenal pathogenesis, and, indeed, SabA production is associated with severe intestinal metaplasia, gastric atrophy, and the development of gastric cancer in both a developed country (United States) and in a developing country (Colombia) [19], suggesting that studies of SabA should be broadened in developing countries. This review summarizes recent information regarding $\mathrm{SabA}$ and gives insight into its role in pathogenesis and adaptation to the host.

\section{Discovery of SabA}

Lewis $b$ antigen $\left(\mathrm{Le}^{\mathrm{b}}\right)$ and related fucosylated $A B O$ blood group antigens are recognized by $\mathrm{BabA}$ [20], and BabA has been believed to be the primary molecule involved in adherence to the gastric mucosa. Significantly, however, a babA deletion mutant that could not bind $\mathrm{ABO} / \mathrm{Le}^{\mathrm{b}}$ blood group antigens still bound to the gastric epithelium in humans and in a Rhesus monkey [16]. Moreover, binding of the babA mutant could not be inhibited by pretreatment of bacteria with soluble
$\mathrm{Le}^{\mathrm{b}}$ antigen. Further analysis showed that the babA mutants preferentially bound to inflamed gastric mucosa. These results implicated the presence of another adhesin, possibly specific to $H$. pylori-infected inflamed tissue, which binds to a receptor distinct from that of BabA.

Using thin layer chromatography, mass spectrometry and nuclear magnetic resonance, Mahdavi et al. identified sialyl-dimeric-Le ${ }^{x}$ (sdiLe $^{x}$ ) glycosphingolipid as a receptor for $H$. pylori and showed that $H$. pylori infection induced formation of $\mathrm{sLe}^{\mathrm{x}}$ antigens in gastric epithelium in humans and in a Rhesus monkey [16]. Using an affinity purification method, this sialyl-dimeric-Le ${ }^{x}$-binding bacterial adhesin was identified as a $70 \mathrm{~K}$ OMP called SabA. Importantly, a paralogous protein, called SabB, was also identified. However, while both $\mathrm{sLe}^{\mathrm{x}}$ and $\mathrm{sLe}^{\mathrm{a}}$ antigen-binding activity was abolished in the sabA mutant, neither were affected in the sabB mutant [16].

\section{Regulation of SabA}

Based on the comparison of the three completed genomes of $H$. pylori, six hop genes (oipA, sabA, sabB, babB, babC and hopZ) are thought to undergo phase variation such that not all strains will produce functional proteins [21-23]. Recent studies also showed that phase variation is a method of regulating BabA production in some strains [24-26]. Functionality is regulated by a slipped strand mispairing mechanism and is mediated by the number of Cysteine-Threonine (CT) dinucleotide repeats in the 5' region of the gene (switch "on" = functional and "off" = nonfunctional).

The genome sequences of $H$. pylori $\mathrm{J} 99$ deposited in GenBank show that $s a b A$ is out of frame with nine CT repeats. Nonetheless, Mahdavi et al. used $\mathrm{J} 99$ as the sLe $\mathrm{e}^{\mathrm{x}}$-binding strain to identify $\operatorname{sabA}$. However, their isolate possessed 10 CT repeats, which would produce a functional SabA protein and could thus explain the sLe ${ }^{x}$ binding [16]. These results show the flexibility of the locus that confers the "on/off" binding properties. The metastability of the SabA adhesin might enable a subpopulation of $H$. pylori to detach from the gastric cells and thereby escape from the most vigorous immune response. This equilibrium between close attachment and detachment might support the establishment of a chronic infection. 
During in vivo passage in a murine model of $H$. pylori infection, both the $s a b A$ and $s a b B$ genes switched from "on" to "off" (27). At four weeks post-inoculation, the switch status was changed in strains recovered from one of three mice infected with strain JK101 (two of nine colonies were changed from $s a b B$ "on" to "off" and one of nine colonies was changed from sabA "on" to "off") and one of three mice infected with strain JK64 (two of nine colonies were changed from sabA "on" to "off"). Interestingly, the bacterial density in mice infected with $H$. pylori strains that were switched "off" was reduced compared with those of mice infected with $H$. pylori strains that showed no change in the switch status. In addition, strains JK101 and JK64 could not keep infecting mice after 12 weeks of inoculation

When multiple colonies derived from one human biopsy specimen were examined for mixed expression, the frequency was highest with SabA, less with $\mathrm{BabB}$ and BabA, and very rare with OipA [19]. In addition, the stability of expression of the OMPs changed during in vitro passages (up to 20 passages) such that OipA > BabA > BabB > SabA. SabA expression frequently switched "on" or "off" suggesting that SabA expression can rapidly respond to changing conditions in the stomach or in different regions of the stomach.

Recently, CT repeats of the sabA gene in Taiwanese strains were analyzed (28). Interestingly, among the $145 \mathrm{H}$. pylori isolates examined, $116(80 \%)$ were sabA gene positive by PCR, but only 45 (31\%) expressed SabA as detected by immunoblot. Importantly, the sequence of $s a b A$ gene positive PCR products from 92 isolates identified that $60 \%(n=55)$ had regular CT repeats whereas the other $40 \%$ ( $n=$ 37) had imperfect CT repeats (i.e., CTTTCTCTATCC) in the $5^{\prime}$ region of the $s a b A$ gene. Among those with a regular CT repeat tract, 18 strains had an in-frame translatable sequence ("on" subtype), but only 13 of these had predicted full-size protein translation. Strains with imperfect CT repeats (37 strains) uniformly had a predicted sabA "on" status, except one isolate, which had a stop codon that interfered with protein translation. However, only 16 of these strains produced detectable SabA protein by immunoblot. Overall, neither the imperfect CT repeats nor the different CT repeats in the $s a b A$ region correlated with SabA production defined by immunoblot.
H. pylori strains with $7 \pm 3 \mathrm{CT}$ repeats in the $5^{\prime}$ region of the $s a b A$ gene are theoretically regarded as "on." However, recent reports from France have shown that sabA expression can be altered by nucleotide changes after the dinucleotide repeats [29]. In addition, there are poly $T$ tracts upstream of the sabA gene, and SabA expression might be also regulated at transcriptional levels, as observed in BabA expression. Therefore, the expression of $s a b A$ is not completely reliant on the number of CT dinucleotide repeats in the 5 ' region of the sabA gene and SabA status based simply on the number of CT repeats should be interpreted with caution.

The presence of the sabA gene does not appear to be universal among $H$. pylori isolates. Although microarray analyses of 15 isolates showed that all possessed the sabA gene [30], $20 \%(29 / 145)$ of Taiwanese strains (28), 14\% (6/43) of French strains (29) and 7\% (7/96) of Dutch strains (31) did not possess the gene. While the sabA-negative genotype might be attributed to false PCR negatives due to subtle mutations among strains in the primer regions, the use of several primer pairs in the Taiwanese and Dutch studies mitigates that risk. Further studies using other methods (e.g., Southern hybridization) will be necessary to determine whether sabA gene negative strains are rare in clinical outcomes.

\section{Major Function of SabA}

SabA was identified as an adhesin, with $s L e^{x}$ and $\mathrm{SLe}^{\mathrm{a}}$ serving as additional functional receptors for $H$. pylori adherence. Aspholm et al. recently reported that clinical $H$. pylori isolates showed "polymorphism" in their ability to bind various sialylated glycans including sdiLe ${ }^{\mathrm{x}}, \mathrm{sLe}^{\mathrm{a}}$ and dialyllactosamine (sLn) (32). They examined 99 Swedish clinical isolates and found that 39 (39\%) could bind to sialylated glycans, and the majority $(87 \%)$ of these isolates could bind all three glycans. Preferential binding to sdiLe ${ }^{x}$ was the most common (24 of 39 isolates, or approximately $60 \%$ of strains tested), but the binding patterns were not uniform among strains (e.g., some strains bound to $s L e^{a}$ beter than sdiLe ${ }^{x}$ and $\left.s L n\right)$. Further analyses using complementation of $s a b A$ mutants confirmed that variation in sialyl binding affinity is an inherent property of the SabA protein. It is likely that the variation is the result of subtle 
differences in sequence, although the specific motifs are yet to be elucidated.

The findings that SabA mediates binding to $\mathrm{sLe}^{\mathrm{x}}$ and $\mathrm{sLe}^{\mathrm{a}}$ are important since $H$. pyloriinduced gastric inflammation and gastric carcinoma are associated with the replacement of nonsialylated Lewis antigens by $s \mathrm{Le}^{\mathrm{x}}$ and $s \mathrm{e}^{\mathrm{a}}[16-$ 18]. Levels of sialylated glycoconjugates are low in healthy gastric mucosa, but $H$. pylori infection elicits gastric mucosal sialylation as part of the chronic inflammatory response. This sialylation correlated with the capacity for SabA-dependent, but not BabA-dependent, binding in situ [16]. Accordingly, high levels of sialylated glycoconjugates have been found in $H$. pyloriinfected individuals, and those levels decreased after eradication of infection and resolution of gastritis.

In contrast to the $L e^{b}$ antigen on glycoproteins, $\mathrm{sLe}^{\mathrm{x}}$ and $\mathrm{sLe}^{\mathrm{a}}$ antigens in membrane glycolipids may protrude less from the cell surface (16). Thus, $H$. pylori adherence during chronic infection might involve two separate receptor-ligand interactions: one by $\mathrm{Le}^{\mathrm{b}}$-mediated adherence through $\mathrm{BabA}$, and a more intimate and weaker $s L e^{x} / s L e^{a}$-mediated adherence by SabA. Mahdavi et al. proposed a scenario for the receptor-ligand interactions [16]. During persistent infection and chronic inflammation (gastritis), $H$. pylori triggers the host tissue to up-regulate the inflammatoryassociated $\mathrm{sLe}^{\mathrm{x}} / \mathrm{sLe} \mathrm{e}^{\mathrm{a}}$ antigens. Then, SabA performs selectin-mimicry by binding the $s e^{x} / s L e^{a}$ glycosphingolipids. At sites of vigorous local inflammatory response, including activated neutrophils carrying sialylated carbohydrates on their surface, some $H$. pylori might lose sLe ${ }^{x}$ binding capacity due to the "on/off" switching of SabA. The "on/off" switching and the weakness of the sLe $/ s L e^{a}$-mediated adherence may benefit $H$. pylori by allowing escape from sites where bactericidal host defense responses are most vigorous. The ability of $H$. pylori strains to adhere to sialylated glycoconjugates expressed during chronic inflammation might thus contribute to virulence and the extraordinary chronicity of $H$. pylori infection.

The minimal structure recognized by the SabA adhesin was determined to be a2-3-linked sialyllactose, irrespective of a terminal or subterminal fucosylation [33,34]. Fucosylation, sialylation, and length of the core chain are parameters that together form a high-affinity binding epitope for SabA. Recent studies using $s a b A$ mutants and sialidase treatment of glycoconjugate arrays showed that SabA is involved in the binding of the extracellular matrix protein laminin [33].

\section{Function of SabA on Neutrophils and Erythrocytes}

Until recently, $H$. pylori was considered a noninvasive enteropathogenic bacterium. However, on several occasions intracellular $H$. pylori have been spotted in cultured epithelial cells, animal models and human gastric biopsy specimens [3539]. In addition, $H$. pylori was found, by in situ hybridization, on erythrocytes in capillaries and post-capillary venules in gastric mucosa of infected humans and Rhesus monkeys, indicating that the bacterium may disseminate into the circulation by way of gastric mucosal capillaries [32]. Therefore, it is meaningful to investigate $H$. pylori-neutrophil and erythrocyte interactions.

Infiltration of neutrophils into the gastric mucosa is a hallmark of chronic gastritis caused by H. pylori. Recently, Unemo et al. found that SabA adhesin has a pivotal role in the nonopsonic activation of human neutrophils [40]. The nonopsonic neutrophil oxidative burst induced by $H$. pylori and adherence of the bacteria is initiated by the binding of $H$. pylori SabA to sialic acidcarrying neutrophil receptors. SabA protein, but not BabA, specifically binds to neutrophils through sialylated carbohydrates and thereby induces an oxidative burst in these cells, causing oxidative damage of the gastric epithelium. The link between receptor binding and oxidative burst involves a G-protein-linked signaling pathway and downstream activation of phosphatidylinositol 3kinase as shown by experiments using signal transduction inhibitors. SabA binding has been identified by flow cytometry, fluorescence microscopy and luminol-enhanced chemiluminescence as the key inducer of oxidative metabolism and as an essential component in the induction of phagocytosis [41]. Overall, SabA adhesin is the key molecule in the nonopsonic activation of human neutrophils and, therefore, is a virulence factor important for the pathogenesis of H. pylori infection.

$H$. pylori has been reported to agglutinate erythrocytes [42]. The activity could be dependent 
on sialic acid since the hemagglutination (HA) activity was lost by prior sialidase treatment of erythrocytes [43]. Recently, Aspholm et al. found that adherence of $H$. pylori to erythrocytes may require molecular mechanisms similar to the sialic acid-dependent in vitro agglutination of erythrocytes (i.e., sialic acid-dependent hemagglutination) [32]. The SabA adhesin was identified as the sialic acid-dependent hemagglutinin based on sialidase-sensitive hemagglutination, binding assays with sialylated glycoconjugates, and analysis of a series of isogenic sabA deletion mutants. The NeuAca23Gal-disaccharide constitutes the minimal sialylated binding epitope required for SabA binding in erythrocytes.

\section{Relationship between SabA and other virulence factors}

Mahadavi et al. initially examined a panel of 95 European clinical isolates for $\mathrm{sLe}^{\mathrm{x}}$ binding [16]. Thirty-three of the 77 (43\%) cagA-positive strains, but only $11 \%$ (2 out of 18 ) of cagA-negative strains ( $P<0.001$ ) bound $s L e^{x}$. In addition, the great majority of the $s L e^{x}$-binding isolates (28 of 35 : $80 \%$ ) also bound the $\mathrm{Le}^{\mathrm{b}}$ antigen. These results suggest that the presence of SabA is closely related to the presence of CagA (or cag PAI) and BabA. However, subsequent studies could not confirm those relationships. For example, CagA and BabA were present in 145 Taiwanese strains, but SabA was positive only for $31 \%$ [28], and no relationship was found between the presence of SabA and CagA (or cag PAI) or BabA in U.S. and Colombian populations [19]. Other reports examining SabA status in French [29] and Dutch [31] populations by PCR-based sequencing for the number of CT repeats in the $s a b A$ gene could not find a relationship between the $s a b A$ "on" status and the presence of the cag PAl and/or babA. Since SabA status is unstable in the stomach [19], it is reasonable that SabA status is not closely related to stable CagA expression.

\section{SabA and pH}

The stomach presents a variety of different microenvironments and the ability to switch various adhesins and surface proteins "on" and "off" may offer survival advantages to the bacteria. For example, deep in the pits the antrum bacteria would be exposed to a different population of cells than those on the luminal surface as well as much smaller fluctuations in $\mathrm{pH}$. In fact, SabA expression was increased in strains obtained from patients with gastric cancer but reduced among those with duodenal ulcer, suggesting that alternating expression may be related to intragastric $\mathrm{pH}$ [19].

Studies of SabA expression support this hypothesis. A microarray study demonstrated that the expression levels of $s a b A$ mRNA decreased in acidic conditions [44]. In addition, H. pylori cultures grown under high acid conditions ( $\mathrm{pH}$ 5.0) for 2 hours showed a dramatic decrease in SabA expression levels compared to those grown at $\mathrm{pH}$ 7.0 [19]. In contrast, the acid exposure did not result in any change in expression levels for BabA, BabB and OipA. When the strains were exposed to $\mathrm{pH} 5.5$ for 20 to 24 hours, the SabA status changed from positive to negative in one strain and the expression of SabA decreased in the other two strains.

Overall, SabA-positive expression was inversely related to the ability of the stomach to secrete acid suggesting that its expression may be regulated by changes in acid secretion and/or in antigens expressed by the atrophic mucosa.

\section{SabA, clinical outcomes and gastric inflammation}

It has been proposed that SabA-positive status is associated with gastric cancer, intestinal metaplasia, and corpus atrophy and negatively associated with duodenal ulcer and neutrophil infiltration. A diverse cohort of strains from 200 patients including 120 from Colombia (40 with gastritis, 40 with duodenal ulcer and 40 with gastric cancer) and 80 from the United States (40 with gastritis and 40 with duodenal ulcer) was examined to determine the relationship between the expression of SabA, BabA, BabB, and OipA and clinical outcome [19]. The prevalence of SabA-positive isolates was $66 \%(53 / 80)$ in gastritis, $88 \%(70 / 80)$ in duodenal ulcer, and $89 \%$ (36/40) in gastric cancer. Multiple logistic regression analysis among these OMPs showed that only SabA status was a predictor of gastric cancer versus duodenal ulcer (odds ratio, 2.8; 95\% confidence interval $=1.2-6.7$ ). Furthermore, SabA-positive status was also closely associated with decreased neutrophil infiltration in both the 
antrum and corpus and with severe intestinal metaplasia and gastric atrophy in the antrum [19].

These results are in agreement with the pathogenesis scenario that Mahdavi et al. proposed previously [16]. Briefly, during persistent infection and chronic inflammation (gastritis), $H$. pylori triggers an alteration in the glycosylation patterns in the gastric mucosa including upregulation of the inflammation-associated $s L e^{x}$ antigens, and SabA binds the sialyl-(di)-Le $e^{x / a}$ glycosphingolipids promoting membrane attachment and apposition. It is proposed that at sites of vigorous local inflammatory response (e.g. severe antral gastric inflammation in duodenal ulcer) $H$. pylori undergoes phase variation and turns "off" SabA-mediated sLe ${ }^{\mathrm{x}}$-binding capacity, which in turn enables $H$. pylori cells to escape intimate contact with sialylated lymphocytes or other defensive immune cells. The ability of $H$. pylori strains to adhere to sialylated glycoconjugates expressed during chronic inflammation might therefore contribute to virulence and the extraordinary chronicity of $H$. pylori infection.

However, one study of $145 \mathrm{H}$. pylori-infected patients from Taiwan reported that the prevalence rate of SabA-positive isolates is similar between patients with different endoscopic diagnoses (33\% [10/30] in duodenal ulcer, 22\% [10/30] in gastric ulcer and 29\% [25/85] in non-ulcer dyspepsia) [28]. In addition, the prevalence rates of gastric atrophy and intestinal metaplasia were not statistically different between patients infected with SabApositive and SabA -negative isolates. Whether there are geographical differences in the relationship between SabA and clinical outcomes or histological changes warrants further attention.

Interestingly, SabA expression affected $H$. pylori density in the gastric mucosa. Patients infected with SabA-positive $H$. pylori isolates $(\mathrm{n}=$ 45) had a higher $H$. pylori density, especially the density over the gastric body, than those $(n=100)$ infected with SabA-negative isolates $(P<0.05)$. Since all Taiwanese patients studied were infected with babA gene positive $H$. pylori isolates, the $H$. pylori density of the infected host was largely determined by the intensity of $L \mathrm{C}^{\mathrm{b}}$ expression on the gastric epithelium [45]. When the relationship between $H$. pylori density and the $s \mathrm{Le}^{\mathrm{x}}$ or $\mathrm{Le}^{\mathrm{b}}$ antigen was examined, $H$. pylori density was found to be higher only in patients expressing gastric
sLe ${ }^{\mathrm{x}}$ antigen (which interacts with SabA) ( $P$ $<0.001$ ) but little or no gastric Le $\mathrm{e}^{\mathrm{b}}$ antigen (which would interact with BabA), and not in those patients with evident expression of gastric $L e^{b}$ antigen. The data suggest that the interaction of SabA and Le $e^{x}$ should have little influence on the $H$. pylori density when $\mathrm{Le}^{\mathrm{b}}$ expression is strong enough to interact with $H$. pylori BabA. This finding indicates that SabA interacting with the sialyl-Le ${ }^{\mathrm{x}}$ antigen can enhance $H$. pylori colonization in those patients with weak or no $\mathrm{Le}^{\mathrm{b}}$ expression.

Other studies indirectly evaluated SabA status by using PCR to assess whether the gene was likely "on" or "off." Lehours et al. [29] reported that combination of the sabA "on" status with hopZ "off" status and ice $A 1$ allele was related to an increased risk for mucosa-associated lymphoid tissue lymphoma. In contrast, de Jong et al. [31] evaluated SabA status by the number of CT repeats in a small study (e.g., 9 gastric cancers) and reported that $s a b A$ "on" status had no relation to clinical outcome. However, as described above, evaluation of SabA status using PCR-based sequencing should be interpreted with caution.

\section{Conclusion}

The importance of SabA on gastroduodenal pathogenesis is increasingly apparent. In the initial stage of infection, binding of BabA to $\mathrm{Le}^{\mathrm{b}} / \mathrm{ABO}$ is probably important; however, when host inflammation increases, expression of $\mathrm{sLe}^{\mathrm{x}}$ increases, and $H$. pylori is likely to adhere to the gastric mucosa with SabA. Importantly, SabA expression most frequently switched "on" or "off", suggesting that SabA expression can rapidly respond to changing conditions in the stomach or in different regions of the stomach. SabA production is indeed reported to be associated with severe intestinal metaplasia, gastric atrophy, and the development of gastric cancer both in the U.S. and Colombia (19); however, there are currently no reports about the importance of SabA in developing countries outside of Colombia. Further studies will be necessary to determine whether SabA plays an important role in other geographic regions and to confirm that $\mathrm{SabA}$ is a true virulence factor, conforming to all three criteria for H. pylori virulence [12]. 


\section{Acknowledgments}

This material is based upon work supported in part by National Institutes of Health (NIH) grants R01 DK62813.

\section{References}

1. Uemura $\mathrm{N}$, Okamoto $\mathrm{S}$, Yamamoto $\mathrm{S}$, Matsumura $\mathrm{N}$, Yamaguchi S, Yamakido M, Taniyama K, Sasaki N, Schlemper RJ (2001) Helicobacter pylori infection and the development of gastric cancer. N Engl J Med 345:784789.

2. Blaser MJ, Perez-Perez GI, Kleanthous H, Cover TL, Peek RM, Chyou PH, Stemmermann GN, Nomura A (1995) Infection with Helicobacter pylori strains possessing $\operatorname{cag} A$ is associated with an increased risk of developing adenocarcinoma of the stomach. Cancer Res 55:2111-2115.

3. Kuipers EJ, Perez-Perez GI, Meuwissen SG, Blaser MJ (1995) Helicobacter pylori and atrophic gastritis: importance of the $\operatorname{cagA}$ status. J Natl Cancer Inst 87:1777-1780.

4. Nomura AM, Lee J, Stemmermann GN, Nomura RY, Perez-Perez Gl, Blaser MJ (2002) Helicobacter pylori CagA seropositivity and gastric carcinoma risk in a Japanese American population. J Infect Dis 186:11381144.

5. Parsonnet J, Friedman GD, Orentreich N, Vogelman H (1997) Risk for gastric cancer in people with CagA positive or CagA negative Helicobacter pylori infection. Gut 40:297-301.

6. Rugge M, Busatto G, Cassaro M, Shiao YH, Russo V, Leandro G, Avellini C, Fabiano A, Sidoni A, Covacci A (1999) Patients younger than 40 years with gastric carcinoma: Helicobacter pylori genotype and associated gastritis phenotype. Cancer 85:2506-2511.

7. van Doorn LJ, Figueiredo C, Megraud F, Pena S, Midolo P, Queiroz DM, Carneiro F, Vanderborght B, Pegado MD, Sanna R, de BW, Schneeberger PM, Correa P, Ng EK, Atherton J, Blaser MJ, Quint WG (1999) Geographic distribution of vacA allelic types of Helicobacter pylori. Gastroenterology 116:823-830.

8. Yamaoka Y, Kodama T, Kita M, Imanishi J, Kashima K, Graham DY (1998) Relationship of vacA genotypes of Helicobacter pylori to cagA status, cytotoxin production, and clinical outcome. Helicobacter 3:241-253.

9. Yamaoka Y, Kodama T, Gutierrez O, Kim JG, Kashima K, Graham DY (1999) Relationship between Helicobacter pylori ice $A, \operatorname{cag} A$, and vacA status and clinical outcome: studies in four different countries. J Clin Microbiol 37:2274-2279.

10. Vilaichone RK, Mahachai V, Tumwasorn S, Wu JY, Graham DY, Yamaoka Y (2004) Molecular epidemiology and outcome of Helicobacter pylori infection in Thailand: a cultural cross roads. Helicobacter 9:453-459.

11. Chattopadhyay S, Datta S, Chowdhury A, Chowdhury S, Mukhopadhyay AK, Rajendran K, Bhattacharya SK, Berg DE, Nair GB (2002) Virulence genes in Helicobacter pylori strains from West Bengal residents with overt $H$. pylori-associated disease and healthy volunteers. J Clin Microbiol 40:2622-2625.

12. Lu H, Yamaoka Y, Graham DY (2005) Helicobacter pylori virulence factors: facts and fantasies. Curr Opin Gastroenterol 21:653-659.
13. Yamaoka $Y$, Souchek J, Odenbreit S, Haas R, Arnqvist A, Boren T, Kodama T, Osato MS, Gutierrez O, Kim JG, Graham DY (2002) Discrimination between cases of duodenal ulcer and gastritis on the basis of putative virulence factors of Helicobacter pylori. J Clin Microbiol 40:2244-2246.

14. Yamaoka Y, Kikuchi S, El-Zimaity HM, Gutierrez O, Osato MS, Graham DY (2002) Importance of Helicobacter pylori oipA in clinical presentation, gastric inflammation, and mucosal interleukin 8 production. Gastroenterology123:414-424.

15. Yamaoka Y, Kwon DH, Graham DY (2000) A M(r) 34,000 proinflammatory outer membrane protein (oipA) of Helicobacter pylori. Proc Natl Acad Sci U S A 97:75337538.

16. Mahdavi J, Sonden B, Hurtig M, Olfat FO, Forsberg L, Roche N, Angstrom J, Larsson T, Teneberg S, Karlsson KA, Altraja S, Wadstrom T, Kersulyte D, Berg DE, Dubois A, Petersson C, Magnusson KE, Norberg T, Lindh F, Lundskog BB, Arnqvist A, Hammarstrom L, Boren T (2002) Helicobacter pylori SabA adhesin in persistent infection and chronic inflammation. Science 297:573-578.

17. Ota $\mathrm{H}$, Nakayama J, Momose M, Hayama M, Akamatsu T, Katsuyama T, Graham DY, Genta RM (1998) Helicobacter pylori infection produces reversible glycosylation changes to gastric mucins. Virchows Arch 433:419-426.

18. Sakamoto S, Watanabe T, Tokumaru T, Takagi $H$, Nakazato H, Lloyd KO (1989) Expression of Lewis a, Lewis $b$, Lewis $x$, Lewis y, siayl-Lewis a, and sialyl-Lewis $x$ blood group antigens in human gastric carcinoma and in normal gastric tissue. Cancer Res 49:745-752.

19. Yamaoka Y, Ojo O, Fujimoto S, Odenbreit S, Haas R, Gutierrez O, El-Zimaity HM, Reddy R, Arnqvist A, Graham DY (2006) Helicobacter pylori outer membrane proteins and gastroduodenal disease. Gut 55:775-781.

20. Ilver D, Arnqvist A, Ogren J, Frick IM, Kersulyte D, Incecik ET, Berg DE, Covacci A, Engstrand L, Boren T (1998) Helicobacter pylori adhesin binding fucosylated histo-blood group antigens revealed by retagging. Science 279:373-377.

21. Alm RA, Ling LS, Moir DT, King BL, Brown ED, Doig PC, Smith DR, Noonan B, Guild BC, deJonge BL, Carmel G, Tummino PJ, Caruso A, Uria-Nickelsen M, Mills DM, Ives C, Gibson R, Merberg D, Mills SD, Jiang Q, Taylor DE, Vovis GF, Trust TJ (1999) Genomic-sequence comparison of two unrelated isolates of the human gastric pathogen Helicobacter pylori. Nature 397:176-180.

22. Oh JD, Kling-Backhed H, Giannakis M, Xu J, Fulton RS, Fulton LA, Cordum HS, Wang C, Elliott G, Edwards J, Mardis ER, Engstrand LG, Gordon JI (2006) The complete genome sequence of a chronic atrophic gastritis Helicobacter pylori strain: evolution during disease progression. Proc Natl Acad Sci USA 103:9999-10004.

23. Tomb JF, White O, Kerlavage AR, Clayton RA, Sutton GG, Fleischmann RD, Ketchum KA, Klenk HP, Gill S, Dougherty BA, Nelson K, Quackenbush J, Zhou L, Kirkness EF, Peterson S, Loftus B, Richardson D, Dodson R, Khalak HG, Glodek A, McKenney K, Fitzegerald LM, Lee N, Adams MD, Hickey EK, Berg DE, Gocayne JD, Utterback TR, Peterson JD, Kelley JM, Cotton MD, Weidman JM, Fujii C, Bowman C, Watthey L, Wallin E, Hayes WS, Borodovsky M, Karp PD, Smith HO, 
Fraser CM, Venter JC (1997) The complete genome sequence of the gastric pathogen Helicobacter pylori. Nature 388:539-547.

24. Colbeck JC, Hansen LM, Fong JM, Solnick JV (2006) Genotypic profile of the outer membrane proteins BabA and BabB in clinical isolates of Helicobacter pylori. Infect Immun 74:4375-4378.

25. Hennig EE, Allen JM, Cover TL (2006) Multiple chromosomal loci for the babA gene in Helicobacter pylori. Infect Immun 74:3046-3051.

26. Solnick JV, Hansen LM, Salama NR, Boonjakuakul JK, Syvanen M (2004) Modification of Helicobacter pylori outer membrane protein expression during experimental infection of rhesus macaques. Proc Natl Acad Sci USA 101:2106-2111.

27. Yamaoka $\mathrm{Y}$, Kita M, Kodama T, Imamura S, Ohno T, Sawai N, Ishimaru A, Imanishi J, Graham DY (2002) Helicobacter pylori infection in mice: Role of outer membrane proteins in colonization and inflammation. Gastroenterology 123:1992-2004.

28. Sheu BS, Odenbreit S, Hung KH, Liu CP, Sheu SM, Yang HB, Wu JJ (2006) Interaction between host gastric SialylLewis $X$ and $H$. pylori SabA enhances $H$. pylori density in patients lacking gastric Lewis $B$ antigen. Am $J$ Gastroenterol 101:36-44.

29. Lehours P, Menard A, Dupouy S, Bergey B, Richy F, Zerbib F, Ruskone-Fourmestraux A, Delchier JC, Megraud $F$ (2004) Evaluation of the association of nine Helicobacter pylori virulence factors with strains involved in low-grade gastric mucosa-associated lymphoid tissue lymphoma. Infect Immun 72:880-888.

30. Salama NR, Guillemin K, McDaniel TK, Sherlock G, Tompkins L, Falkow S (2000) A whole-genome microarray reveals genetic diversity among Helicobacter pylori strains. Proc Natl Acad Sci USA 97:14668-14673.

31. de Jonge R, Pot RG, Loffeld RJ, van Vliet $A H$, Kuipers EJ, Kusters JG (2004) The functional status of the Helicobacter pylori $s a b B$ adhesin gene as a putative marker for disease outcome. Helicobacter 9:158-164.

32. Aspholm M, Olfat FO, Norden J, Sonden B, Lundberg C, Sjostrom R, Altraja S, Odenbreit S, Haas R, Wadstrom T, Engstrand L, Semino-Mora C, Liu H, Dubois A, Teneberg $S$, Arnqvist A, Boren T (2006) SabA is the $H$. pylori hemagglutinin and is polymorphic in binding to sialylated glycans. PLoS Pathog 2:e110.

33. Roche $\mathrm{N}$, Angstrom J, Hurtig M, Larsson $\mathrm{T}$, Boren $\mathrm{T}$, Teneberg S (2004) Helicobacter pylori and complex gangliosides. Infect Immun 72:1519-1529.

34. Walz A, Odenbreit S, Mahdavi J, Boren T, Ruhl S (2005) Identification and characterization of binding properties of Helicobacter pylori by glycoconjugate arrays. Glycobiology 15:700-708.

35. Amieva MR, Salama NR, Tompkins LS, Falkow S (2002) Helicobacter pylori enter and survive within multivesicular vacuoles of epithelial cells. Cell Microbiol 4:677-690.
36. Bjorkholm B, Zhukhovitsky V, Lofman C, Hulten K, Enroth $\mathrm{H}$, Block M, Rigo R, Falk P, Engstrand L (2000) Helicobacter pylori entry into human gastric epithelial cells: A potential determinant of virulence, persistence, and treatment failures. Helicobacter 5:148-154.

37. Kwok T, Backert S, Schwarz H, Berger J, Meyer TF (2002) Specific entry of Helicobacter pylori into cultured gastric epithelial cells via a zipper-like mechanism. Infect Immun 70:2108-2120.

38. Oh JD, Karam SM, Gordon JI (2005) Intracellular Helicobacter pylori in gastric epithelial progenitors. Proc Natl Acad Sci USA 102:5186-5191.

39. Semino-Mora C, Doi SQ, Marty A, Simko V, Carlstedt I, Dubois A (2003) Intracellular and interstitial expression of Helicobacter pylori virulence genes in gastric precancerous intestinal metaplasia and adenocarcinoma. $\mathrm{J}$ Infect Dis 187:1165-1177.

40. Unemo M, spholm-Hurtig M, Ilver D, Bergstrom J, Boren T, Danielsson D, Teneberg S (2005) The sialic acid binding SabA adhesin of Helicobacter pylori is essential for nonopsonic activation of human neutrophils. J Biol Chem 280:15390-15397.

41. Petersson C, Forsberg M, Aspholm M, Olfat FO, Forslund T, Boren T, Magnusson KE (2006) Helicobacter pylori SabA adhesin evokes a strong inflammatory response in human neutrophils which is down-regulated by the neutrophil-activating protein. Med Microbiol Immunol (Berl) 195:195-206.

42. Emody L, Carlsson A, Ljungh A, Wadstrom T (1988) Mannose-resistant haemagglutination by Campylobacter pylori. Scand J Infect Dis 20:353-354.

43. Evans DG, Evans DJ, Jr., Moulds JJ, Graham DY (1988) $\mathrm{N}$-acetylneuraminyllactose-binding fibrillar hemagglutinin of Campylobacter pylori: a putative colonization factor antigen. Infect Immun 56:2896-2906.

44. Merrell DS, Goodrich ML, Otto G, Tompkins LS, Falkow S (2003) $\mathrm{pH}$-regulated gene expression of the gastric pathogen Helicobacter pylori. Infect Immun 71:35293539.

45. Sheu BS, Sheu SM, Yang HB, Huang AH, Wu JJ (2003) Host gastric Lewis expression determines the bacterial density of Helicobacter pylori in babA2 genopositive infection. Gut 52:927-932.

Corresponding Author: Yoshio Yamaoka, Department of Medicine-Gastroenterology, Michael E. DeBakey Veterans Affairs Medical Center, 2002 Holcombe Blvd., (111D) Rm 3A-320, Houston, Texas 77030 USA, Tel. 713-794-7597, Fax. 713-795-4471

E-mail: yyamaoka@bcm.tmc.edu

Conflict of interest: No conflict of interest is declared. 